\title{
Characterizing 5-hydroxymethylcytosine in (1) CrossMark human prefrontal cortex at single base resolution
}

\author{
Jeffrey A. Gross' ${ }^{1}$, Alain Pacis ${ }^{2,3}$, Gary G. Chen ${ }^{1}$, Luis B. Barreiro ${ }^{2,3}$, Carl Ernst ${ }^{1}$ and Gustavo Turecki ${ }^{*}$
}

\begin{abstract}
Background: The recent discovery that methylated cytosines are converted to 5-hydroxymethylated cytosines (5hmC) by the family of ten-eleven translocation enzymes has sparked significant interest on the genomic location, the abundance in different tissues, the putative functions, and the stability of this epigenetic mark. $5 \mathrm{hmC}$ plays a key role in the brain, where it is particularly abundant and dynamic during development.

Results: Here, we comprehensively characterize $5 \mathrm{hmC}$ in the prefrontal cortices of 24 subjects. We show that, although there is inter-individual variability in $5 \mathrm{hmC}$ content among unrelated individuals, approximately $8 \%$ of all CpGs on autosomal chromosomes contain 5hmC, while sex chromosomes contain far less. Our data also provide evidence suggesting that $5 \mathrm{hmC}$ has transcriptional regulatory properties, as the density of $5 \mathrm{hmC}$ was highest in enhancer regions and within exons. Furthermore, we link increased $5 \mathrm{hmC}$ density to histone modification binding sites, to the gene bodies of actively transcribed genes, and to exon-intron boundaries. Finally, we provide several genomic regions of interest that contain gender-specific $5 \mathrm{hmC}$.

Conclusions: Collectively, these results present an important reference for the growing number of studies that are interested in the investigation of the role of $5 \mathrm{hmC}$ in brain and mental disorders.
\end{abstract}

Keywords: 5-hydroxymethylcytosine, Prefrontal cortex, Human, Epigenetics, Brain

\section{Background}

In mammalian cells, 5 -methylcytosine $(5 \mathrm{mC})$ has been the most widely studied epigenetic mark, and has long been regarded as a stable DNA modification. Recently, however, research has shown that $5 \mathrm{mC}$ can be oxidized to 5hydroxymethylcytosine $(5 \mathrm{hmC})$ by the ten-eleven translocation (TET) family of proteins [1-3]. $5 \mathrm{hmC}$ has been shown to be most abundant in brain tissue [4-6] and to influence transcriptional regulatory activity $[7-10]$.

Although its role is not yet completely understood, $5 \mathrm{hmC}$ has been increasingly investigated in neuropsychiatric phenotypes, likely due to its involvement in neuronal development and enrichment in brain tissue $[11,12]$. In humans, global levels of $5 \mathrm{hmC}$ have been shown to be reduced in Alzheimer's disease [13], while site-specific differences have been demonstrated in

\footnotetext{
*Correspondence: gustavo.turecki@mcgill.ca

${ }^{1}$ McGill Group for Suicide Studies, Douglas Mental Health University Institute, 6875 boul. Lasalle, Montreal, Quebec, Canada

Full list of author information is available at the end of the article
}

autism spectrum disorder [14], Huntington's disease [15], and psychosis [16]. In mouse models, genome-wide alterations have also been observed in Huntington's disease [17], as well as in fragile $\mathrm{X}$-associated tremor/ataxia syndrome [18]. Taken together, these observations suggest a significant role of $5 \mathrm{hmC}$ in the etiology of neuropsychiatric diseases.

To date, however, investigations of $5 \mathrm{hmC}$ in the human brain have either been in very small samples or have utilized low-throughput techniques. Here, we use a sample with good power and sequencing resolution to provide insight into genomic characteristics of $5 \mathrm{hmC}$ in the brain. Although we observe sizable variability of $5 \mathrm{hmC}$ between subjects, lending to the hypothesis of a dynamic cytosine-modifying pathway, we also demonstrate a strong association between stable $5 \mathrm{hmC}$ and epigenetic properties. In its entirety, the descriptive data presented here provide a map of $5 \mathrm{hmC}$ at single base resolution, which is of interest to future studies of $5 \mathrm{hmC}$ in the cortex of the human brain.

\section{Biomed Central}

(c) 2015 Gross et al. Open Access This article is distributed under the terms of the Creative Commons Attribution 4.0 International License (http://creativecommons.org/licenses/by/4.0/), which permits unrestricted use, distribution, and reproduction in any medium, provided you give appropriate credit to the original author(s) and the source, provide a link to the Creative Commons license, and indicate if changes were made. The Creative Commons Public Domain Dedication waiver (http://creativecommons.org/publicdomain/zero/1.0/) applies to the data made available in this article, unless otherwise stated. 


\section{Results}

\section{Sequencing characteristics}

Several high-throughput epigenetic sequencing protocols rely on restriction enzymes, such as MspI and HpaII. In this study, we used AbaSI, an enzyme that recognized glucosyl-modified cytosines and created a cut site 11-13 base pairs downstream of this modified cytosine [19], followed by sequencing to conduct a whole-genome $5 \mathrm{hmC}$ analysis at single-base resolution. We initially studied DNA from prefrontal cortical samples from 19 male subjects. As expected, our sequencing results consistently showed that $40-45 \%$ of all reads contained cytosine and guanine bases, respectively, at the 11th and 12th positions after the adaptor sequence (Fig. 1a). This confirmed the specificity of the enzyme, as $5 \mathrm{hmC}$ occurs almost exclusively in CpG sequences in both fetal and adult mammalian brain $[8,9]$. This value was also expected since, methodologically, half of the sequenced reads were not expected to contain a $\mathrm{CpG}$ dinucleotide at these positions and, therefore, were discarded during

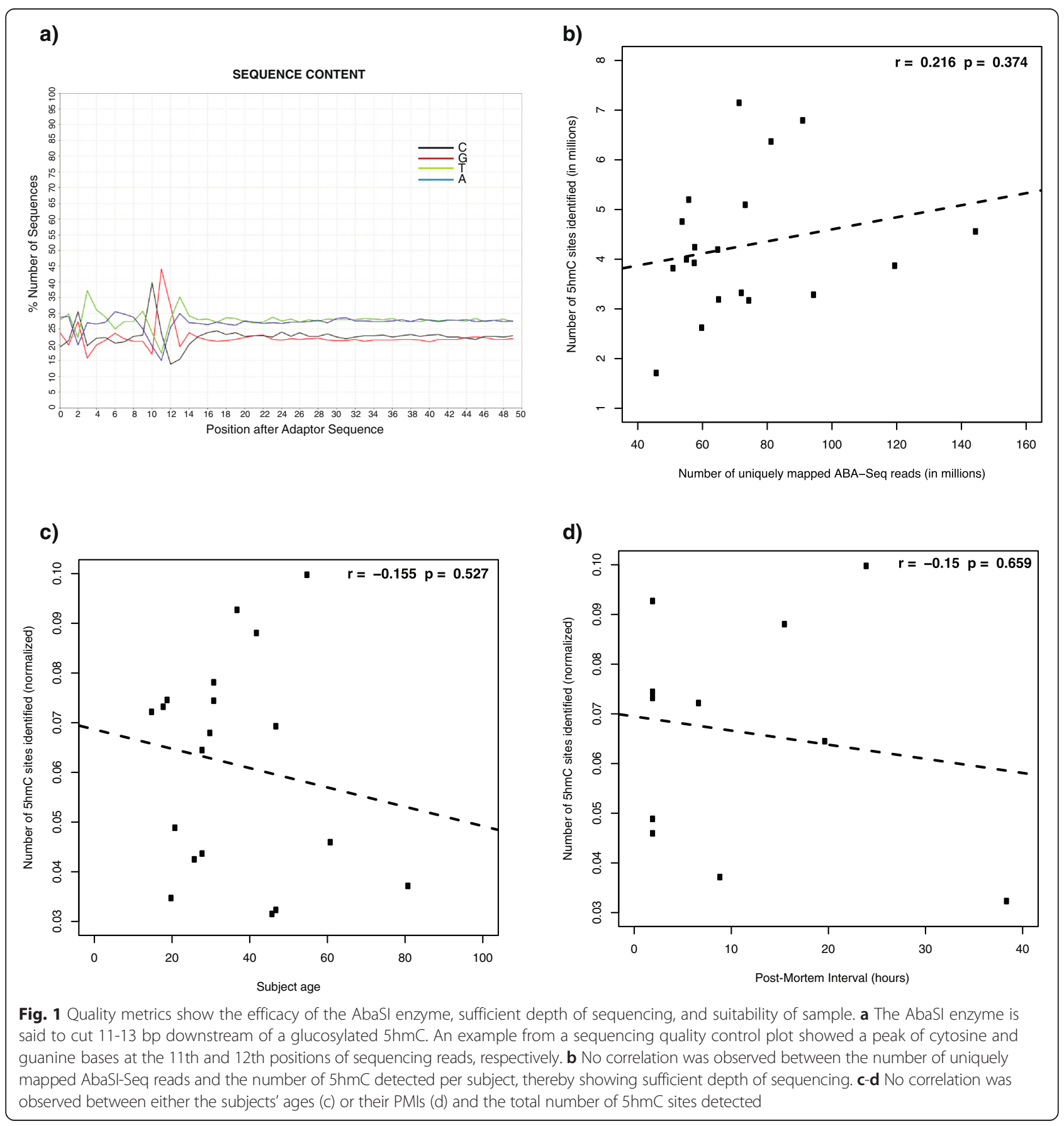


bioinformatic analyses. We generated an average of $109,394,675$ single end reads per subject, of which an average of $82,210,131 \pm 4,498,459$ reads passed multiple filtering steps and were used to generate the data presented here (Additional file 1). We plotted the number of aligned reads against the number of unique $5 \mathrm{hmC}$ sites detected and found that 60-80 million reads was an optimal range; there were four subjects with $>90$ million uniquely aligned reads and the number of $5 \mathrm{hmC}$ sites in these subjects was not notably different from most subjects with 60-80 million reads (Fig. 1b). This sugested diminishing returns of $5 \mathrm{hmC}$ detectabiliy under these experimental parameters after $\sim 60-80$ million reads. We next assessed the effects of age and post-mortem delay, two factors that might affect $5 \mathrm{hmC}$ leves, and found no signficant correlation (Fig. 1c, d).

\section{Genome-wide inter-individual differences of $5 \mathrm{hmC}$}

A major focus of this study was to determine whether $5 \mathrm{hmC}$ sites were present at similar genomic locations in brain tissue from different individuals. We first investigated what proportion of all $5 \mathrm{hmC}$ sites were common to multiple individuals. We identified a total of 17,368,538 unique $5 \mathrm{hmC}$ sites across 19 individuals, of which $81.3 \%$ were also identified in a previous study examining $5 \mathrm{hmC}$ content in the prefrontal cortex using Tet-assisted bisulfite sequencing (TAB-Seq) [9]. We found that $41.7 \%$ of all $5 \mathrm{hmC}$ sites observed were found in at least 5 individuals, whereas $12.2 \%$ of all $5 \mathrm{hmC}$ sites were common to at least 10 individuals, and only $1.3 \%$ were common to at least 15 individuals (Additional file 2). As a point of comparison, we investigated the proportion of $5 \mathrm{mC}$ sites common to multiple individuals by whole genome bisulfite sequencing (WGBS). $5 \mathrm{mC}$ showed considerable stability across the 19 subjects investigated when considering 5,10 , or 15 individuals, however we observed an abrupt decrease in the percentage of sites common to all 19 subjects (Additional file 3). Although these data indicated that $5 \mathrm{hmC}$ is considerably more variable than $5 \mathrm{mC}$, they also suggested a relative degree of stability of $5 \mathrm{hmC}$ sites in brain tissue from different individuals.

We next assessed the probability of detecting similar $5 \mathrm{hmC}$ sites between any two individuals. To do so, we selected two representative samples with respect to sequencing depth and number of unique $5 \mathrm{hmC}$ sites. We subsequently calculated the hypergeometric probability of detecting the same $5 \mathrm{hmCs}$ in sequencing reads across independent samples. First, we estimated the total number of $5 \mathrm{hmC}$ sites in the human brain genome to be around 27 million, based on previously published data [9]. We observed 6,793,582 and 3,818,749 total $5 \mathrm{hmC}$ sites in each of the representative samples considered in this analysis, of which $1,999,4935 \mathrm{hmC}$ sites were common to both subjects $\left(P<3.34 \mathrm{e}^{-178}\right)$, suggesting that the pattern of common $5 \mathrm{hmC}$ sites observed between samples was not random.

\section{Chromsomal distribution of $5 \mathrm{hmC}$ in human prefrontal cortex}

While we observed a strong overlap of $5 \mathrm{hmC}$ across individuals, we opted to perform the following analyses according to three levels of stringency; low, intermediate, and high stringencies, which represented all $5 \mathrm{hmC}$ sites common to $\sim 25,50$, and $75 \%$ of the total sample, respectively. In the low stringency group, an average of $25.7 \pm 1.1$ $\%$ of all autosomal CGs contained a hydroxymethyl mark, while $7.4 \pm 2.3 \%$ and $0.8 \pm 0.4 \%$ of CGs contained a hydroxymethyl mark in the intermediate and high stringency groups, respectively (Fig. 2a-f, Additional file 4).

The total number of $5 \mathrm{hmC}$ sites analyzed in the intermediate stringency model was 2,121,951, which was slightly lower than the average number of $5 \mathrm{hmC}$ sites observed in any single individual $(4,277,308 \pm 319,846)$. Furthermore, $94.75 \%$ of sites in the intermediate stringency were also present in a recent TAB-Seq study of the prefrontal cortex of one individual human female [9]. For these reasons, we focused further analyses on the intermediate stringency model.

\section{5hmC densities across chromosomal features}

We next determined the density of $5 \mathrm{hmC}$ on each chromsome and within specific chromosomal features. We defined the density as being the total number of $5 \mathrm{hmC}$ sites corrected for the total number of CGs on the chromosome and the chromosome length. We observed the density of $5 \mathrm{hmC}$ to be quite stable across autosomal chromosomes, although a relative increase in density was observed in chromosomes 18, 20, 21, and 22 compared to other chromosomes. Interestingly, in comparison to the autosomes, the density of $5 \mathrm{hmC}$ was greatly decreased in the sex chromosomes and increased in mitochondrial DNA (Fig. 3a).

The density of $5 \mathrm{hmC}$ across chromosomal features is of interest as it may provide insight into its potential functional properties. Genomic features were defined based on GRCh37/hg19 genomic annotations downloaded from the UCSC browser and Ensembl release 75. Our data showed an increase in $5 \mathrm{hmC}$ density in both poised and active enhancers, as well as in exons (Fig. 3b). The increase in $5 \mathrm{hmC}$ in these regions has been previously observed in human embryonic stem cells [20, 21] and both fetal and adult mouse brain [8]. In contrast, $5 \mathrm{hmC}$ density appeared to be relatively depleted in transcription start sites (TSS), CpG shores, and, most strikingly, CpG islands and both long and short interspersed elements (LINEs and SINEs, respectively). 


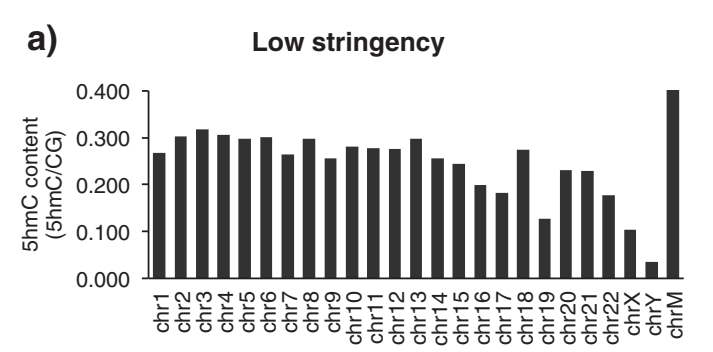

b)

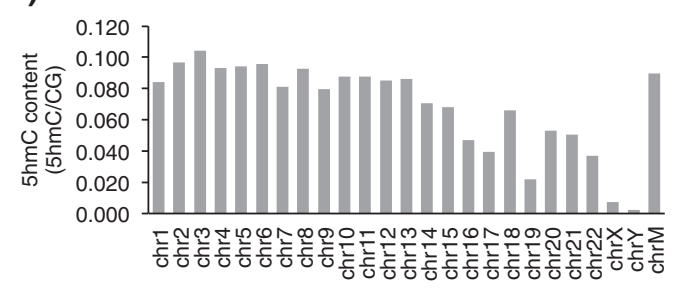

c)

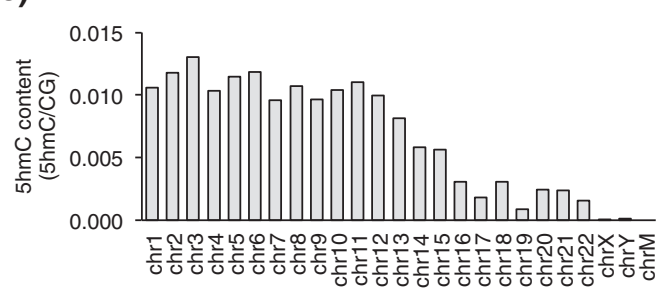

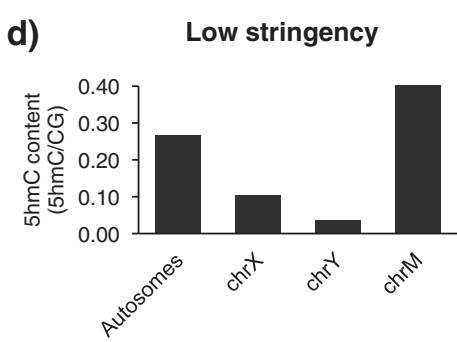

e) Intermediate stringency

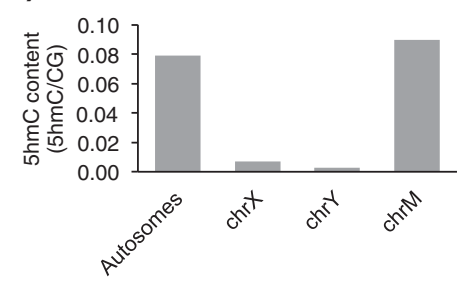

f)

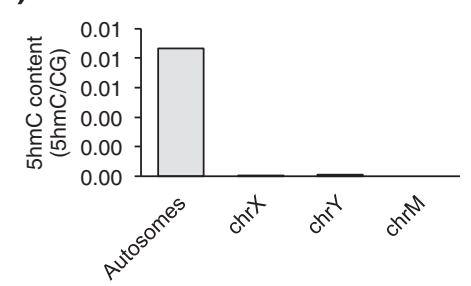

Fig. 2 The total number of hydroxymethylated CGs per chromosome decreased exponentially with increasing stringency. Plots displaying the total number of $5 \mathrm{hmC}$ sites for each chromosome corrected for the total number of CGs on the respective chromosome, for low (a), intermediate (b), and high (c) stringencies. Summary plots for autosomes, sex chromosomes, and mitochondrial DNA are shown for each respective stringency (d-f)

\section{Potential functional properties of $5 \mathrm{hmC}$}

The observed increase in $5 \mathrm{hmC}$ density in enhancer regions of the genome led to the hypothesis that $5 \mathrm{hmC}$ may also be associated with histone marks on an individual basis. Using data from chromatin maps in the frontal lobe [22], we calculated the mean $5 \mathrm{hmC}$ levels in contiguous 100 bp bins flanking the proposed histone modification binding site. Consistent with the results showing increased density of $5 \mathrm{hmC}$ in poised enhancer regions (Fig. 3b), we also observed an increase in $5 \mathrm{hmC}$ density at the H3K4me1 ChIP-Seq peak (Fig. 3c). In addition, opposite results were seen at both the H3K4me3 and H3K27ac ChIP-Seq peaks, as the density of $5 \mathrm{hmC}$ decreased at the midpoint for both histone marks (Fig. 3c).

Similar to histone and cytosine methylation, $5 \mathrm{hmC}$ may be an epigenetic mark that associates with altered gene transcription. To explore this possibility further, we compared $5 \mathrm{hmC}$ densities across the gene body to available RNA-Seq data from the prefrontal cortex of 11 independent control samples [23]. We plotted $5 \mathrm{hmC}$ density along the gene body for all genes separated in quartiles by their expression levels. We found that $5 \mathrm{hmC}$ was enriched in the gene bodies of highly expressed genes (Fig. 4a). This was consistent with similar associations between gene body $5 \mathrm{hmC}$ and actively transcribed genes reported previously in limited human and mouse brain samples [8,9], as well as mouse neuronal cells [7]. In addition to gene body $5 \mathrm{hmC}$, genes with the highest expression also showed the greatest reduction in $5 \mathrm{hmC}$ at the TSS (Fig. 4a), even though the TSS of highly expressed genes had an overall increase in CpG density compared to the TSS of lowly expressed genes.

Along with the putative function of $5 \mathrm{hmC}$ in regulating gene transcription, two previous reports have also suggested an association between $5 \mathrm{hmC}$ and exon-intron boundaries $[9,24]$. We looked at $5 \mathrm{hmC}$ content across 20 bp flanking the 5' and 3' ends of 144,157 internal exons spanning 20,745 genes. We observed patterns of increased $5 \mathrm{hmC}$ at exon-intron boundaries, specifically at the 5' splice site and four bases downstream (Fig. 4b). This spike in $5 \mathrm{hmC}$ was not strand-specific, as similar results were obtained on both the sense and anti-sense strands (Fig. 4c). The present results may be indicative of a potential splicing mechanism, perhaps through the association of $5 \mathrm{hmC}$ and the CCCTC-binding factor (CTCF). Not only is CTCF a transcription factor that has been linked to 

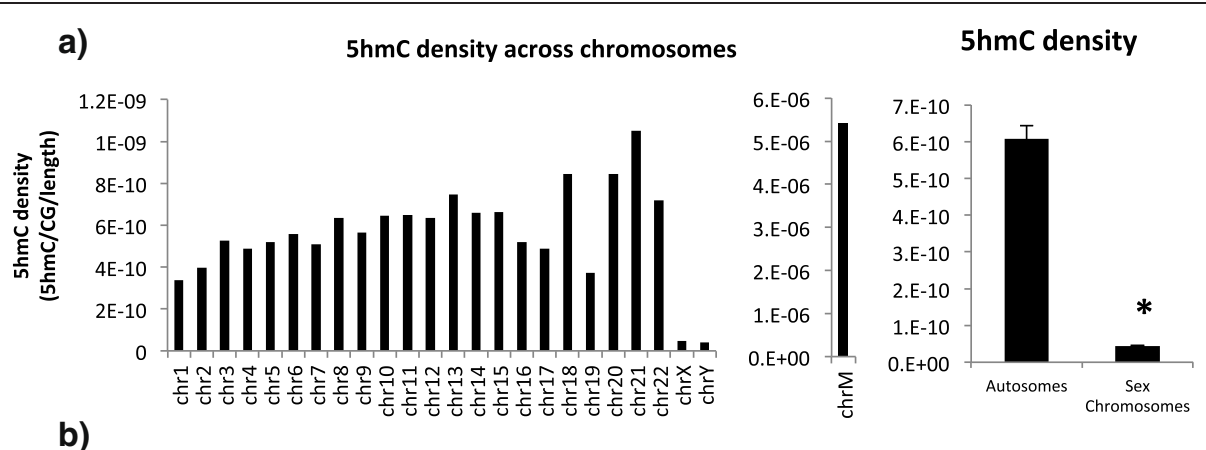

b)

$5 \mathrm{hmC}$ density across genomic features

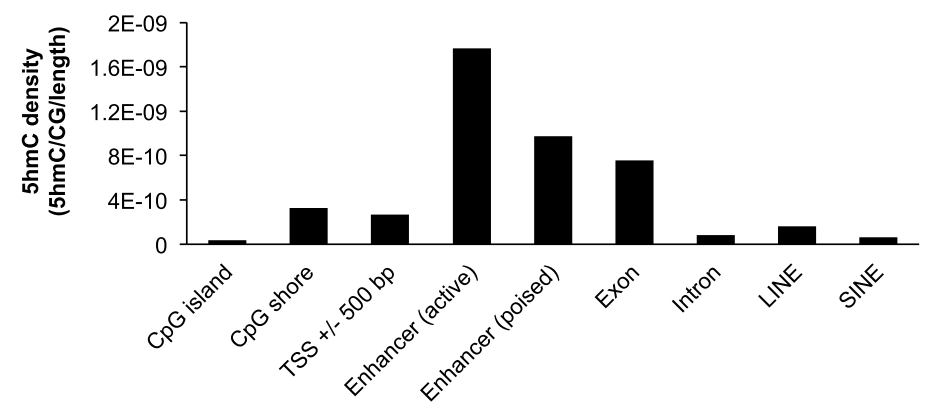

c)

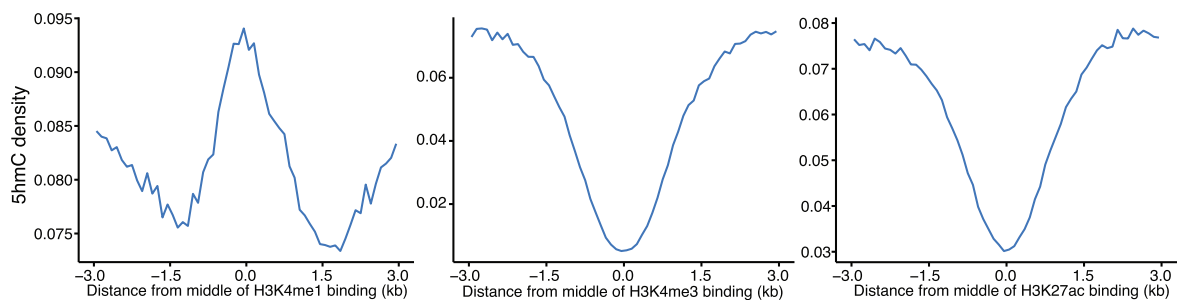

Fig. 35 hmC densities on chromosomes, within genomic features, and around histone modification binding sites. a 5hmC density remained relatively stable from one chromosome to the next, although the density appeared to show more variability on shorter chromosomes. 5 hmC density was also far greater on autosomal chromosomes than the two sex chromosomes (two-tailed $P<0.0001$ ). b 5 hmC was most highly abundant in enhancer elements and gene bodies, while its density decreased in CpG islands, the TSS, and repetitive elements. c Increased $5 \mathrm{hmC}$ was observed at the H3K4me1 binding site, while the opposite was true for both H3K4me3 and H3K27ac binding sites

alternative splicing by regulating the activity of RNA polymerase II [25], but it has also been shown to interact with $5 \mathrm{hmC}$ and TET enzymes in both mouse and human embryonic stem cells [21, 26, 27]. Taken together, these results provide an interesting avenue for further research into alternative splicing mechanisms.

\section{Brain $5 \mathrm{hmC}$ clusters are predominant in genes associated} with neurodevelopment

Given the association of $5 \mathrm{hmC}$ with regulatory processes, we next wanted to determine whether $5 \mathrm{hmC}$ aggregated in specific genes. We defined a cluster as being a region containing at least three $5 \mathrm{hmCs}$, each within $200 \mathrm{bp}$ of each other. Using the $2,121,9515 \mathrm{hmC}$ sites in the intermediate stringency category, we identified a total of 65,898 clusters. The midpoint of each cluster was then associated to the TSS of the nearest gene. A total of 8,713 genes were analyzed using GeneTrail [28] for gene ontology (GO). A variety of terms related to cellular, metabolic, and signaling processes were significantly associated with $5 \mathrm{hmC}$ clusters. Furthermore, of particular interest, we observed an enrichment of terms associated with neurological processes and neurodevelopment, including terms related to nervous system development, neurogenesis, and gliogenesis (Table 1). Additional significant terms included those related to other areas of development and epigenetic processes. The complete list of GO terms can be found in Additional file 5.

Sex differences in $5 \mathrm{hmC}$ in the human prefrontal cortex In males, the density of $5 \mathrm{hmC}$ on the sex chromosomes $\left(\right.$ mean $=4.43 \mathrm{e}^{-11} \pm 2.37 \mathrm{e}^{-12}$ ) was nearly 10 -fold lower (two-tailed $P<0.0001$ ) compared to the autosomes $\left(\right.$ mean $=6.08 \mathrm{e}^{-10} \pm 3.56 \mathrm{e}^{-11}$ ) (Fig. 3a), suggesting differential $5 \mathrm{hmC}$ patterns between chromosome types. To further explore this finding, we performed another 

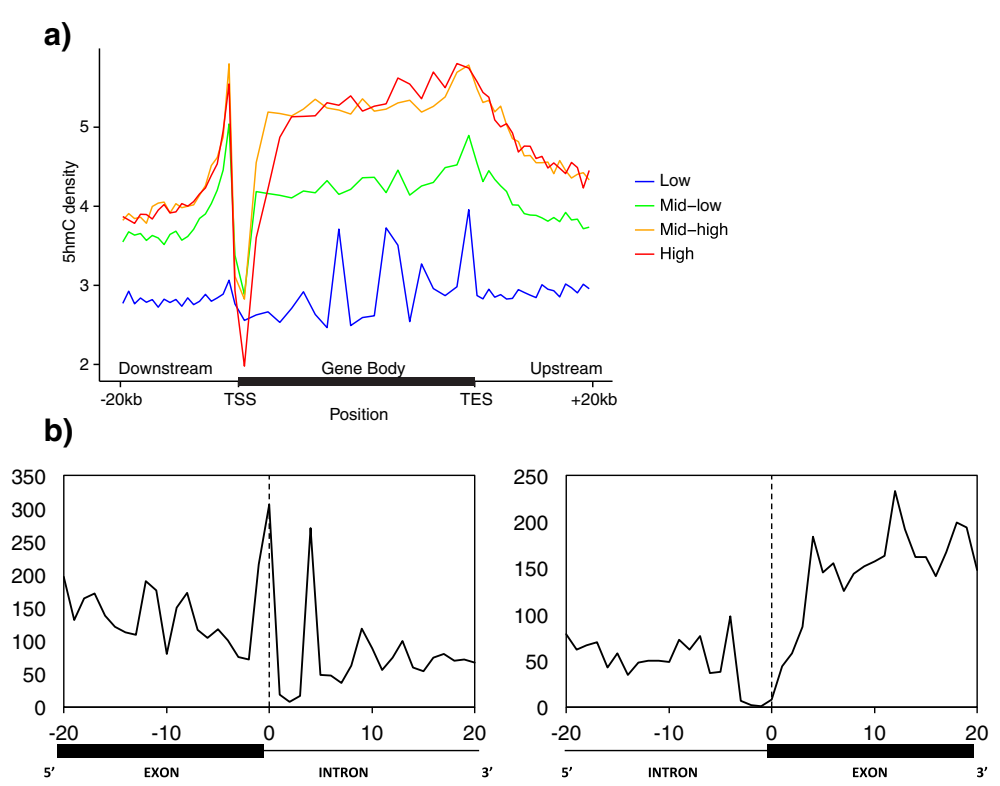

c)
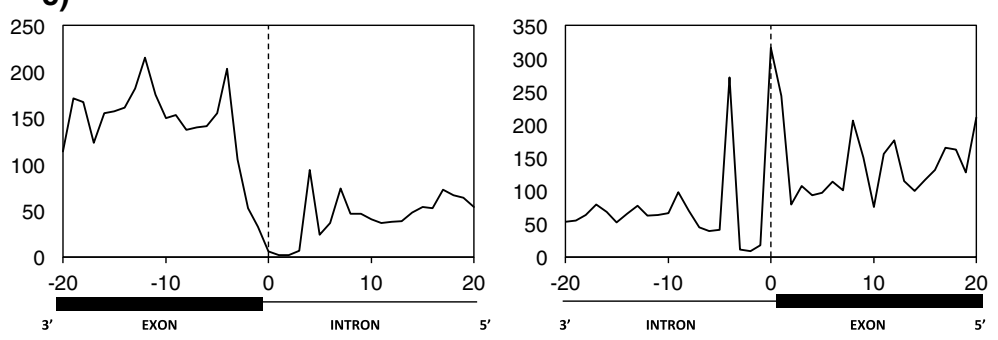

Fig. $45 \mathrm{hmC}$ was enriched in the gene bodies of highly expressed genes and at exon-intron boundaries. a $5 \mathrm{hmC}$ density was plotted against genomic location for all genes separated in quartiles by their expression levels. 5hmC showed the greatest decrease in density at the TSS for highly expressed genes, while also showing the greatest increase in density in the gene body for this same group. The opposite trend was seen in genes in the lowest quartile of expression. An interesting spike in $5 \mathrm{hmC}$ density was also observed at the TES in all quartiles of expression. $\mathbf{b} 5 \mathrm{hmC}$ density is increased in the exons on the $5^{\prime}$ and $3^{\prime}$ ends of exon-intron boundaries. c A similar pattern of $5 \mathrm{hmC}$ density was also seen on the anti-sense strand of corresponding exon-intron boundaries. (TSS = transcription start site; TES = transcription end site)

AbaSI-Seq analysis using DNA from the prefrontal cortex from females $(n=5)$. Similar to our experiment in males, we used all sites common to a proportion of subjects (at least 3 individuals), which is equivalent to the intermediate stringency model, to plot the density of $5 \mathrm{hmC}$ across all chromosomes. As in the analysis with males only, the density of $5 \mathrm{hmC}$ was increased on chromosomes 18, 20, 21, and 22, while remaining quite stable across all other autosomes (Fig. 5a). Interestingly, the difference in $5 \mathrm{hmC}$ density between males and females became larger as the chromosome size decreased (Fig. 5b).

To identify differences in $5 \mathrm{hmC}$ patterns between males and females, we reasoned that differential clusters of $5 \mathrm{hmC}$ on any chromosome might indicate potential regulatory regions. As such, to identify $5 \mathrm{hmC}$ clusters unique to males, we sampled five randomly selected sets of 5 males and compared $5 \mathrm{hmC}$ sites in each set to those found in the females. We identified 27,410 5hmC clusters, associated with 7,064 genes, which were both unique to males and common in all five randomly selected sets. Subsequent GO analysis identified an enrichment in genes related to anatomical and system development, among others (Additional file 6). To determine female-specific $5 \mathrm{hmC}$ clusters, we compared all $5 \mathrm{hmC}$ sites on autosomes and the sex chromosomes, found in both the female $(11,054,815$ sites $)$ and male samples $(17,368,5385 \mathrm{hmC}$ sites). In doing so, we identified $707,5495 \mathrm{hmC}$ sites unique to the females included in this study, which might represent gender-specific $5 \mathrm{hmC}$ sites. A cluster analysis of these $5 \mathrm{hmC}$ sites specific to females indicated a total of 12,034 clusters, which were associated to 4,417 genes. GO analysis identified terms related to organ morphogenesis, anatomical structure development, and system development, among others (Table 2, Additional file 7). Of particular interest were 2 clusters on the anti-Müllerian Hormone $(\mathrm{AMH})$ gene, one of which contained three $5 \mathrm{hmC}$ sites within a $188 \mathrm{bp}$ region spanning intron 2 and 
Table $1 \mathrm{GO}$ terms related to neurological, epigenetic, and developmental processes from cluster analysis in intermediate stringency

\begin{tabular}{|c|c|c|c|c|}
\hline Neurological & Expected & Observed & p-value (fdr) & Enrichment \\
\hline Neurological system process & 616.197 & 485 & $2.86 \mathrm{E}-13$ & down \\
\hline Neurogenesis & 332.402 & 396 & 7.11E-06 & up \\
\hline Neuron projection & 190.242 & 237 & 1.74E-05 & up \\
\hline Generation of neurons & 309.405 & 366 & 4.80E-05 & up \\
\hline Neuron differentiation & 281.183 & 333 & 0.000109238 & up \\
\hline Axon & 91.4627 & 117 & 0.00142957 & up \\
\hline Cell morphogenesis involved in neuron differentiation & 124.389 & 151 & 0.00563766 & up \\
\hline Neuron projection morphogenesis & 127.525 & 154 & 0.00684608 & up \\
\hline Glial cell differentiation & 39.721 & 53 & 0.0202685 & up \\
\hline Regulation of neuron differentiation & 93.0307 & 113 & 0.0215321 & up \\
\hline Gliogenesis & 46.5153 & 60 & 0.0317942 & up \\
\hline Regulation of neurogenesis & 113.414 & 134 & 0.0340942 & up \\
\hline Epigenetic & Expected & Observed & p-value (fdr) & Enrichment \\
\hline Protein amino acid methylation & 25.0869 & 35 & 0.0332904 & up \\
\hline Lysine $\mathrm{N}$-methyltransferase activity & 18.8152 & 27 & 0.0455873 & up \\
\hline Protein-lysine N-methyltransferase activity & 18.8152 & 27 & 0.0455873 & up \\
\hline Histone-lysine N-methyltransferase activity & 18.8152 & 27 & 0.0455873 & up \\
\hline $\mathrm{N}$-methyltransferase activity & 29.7907 & 40 & 0.0461752 & up \\
\hline Histone $\mathrm{H} 2 \mathrm{~A}$ acetylation & 6.27173 & 11 & 0.0496797 & up \\
\hline Development & Expected & Observed & p-value (fdr) & Enrichment \\
\hline Sensory perception of smell & 189.197 & 33 & $1.42 \mathrm{E}-66$ & down \\
\hline Sensory perception of chemical stimulus & 209.58 & 50 & $3.33 \mathrm{E}-61$ & down \\
\hline Sensory perception & 389.37 & 253 & $6.42 \mathrm{E}-22$ & down \\
\hline Developmental process & 1748.24 & 1912 & 1.16E-08 & up \\
\hline System development & 1318.63 & 1463 & 2.08E-08 & up \\
\hline Anatomical structure development & 1460.79 & 1608 & 4.39E-08 & up \\
\hline Multicellular organismal development & 1593.54 & 1744 & $6.81 \mathrm{E}-08$ & up \\
\hline Nervous system development & 603.131 & 699 & $1.78 \mathrm{E}-07$ & up \\
\hline Regulation of developmental process & 413.934 & 494 & 1.94E-07 & up \\
\hline Positive regulation of developmental process & 182.925 & 236 & 3.04E-07 & up \\
\hline Neuron development & 205.399 & 249 & 0.000157004 & up \\
\hline Forebrain development & 90.4174 & 118 & 0.000419088 & up \\
\hline Central nervous system development & 239.371 & 282 & 0.000802517 & up \\
\hline Neuron projection development & 166.723 & 200 & 0.00211809 & up \\
\hline Sensory organ development & 129.093 & 154 & 0.0128753 & up \\
\hline Regulation of nervous system development & 123.344 & 146 & 0.0233886 & up \\
\hline Brain development & 163.588 & 189 & 0.0279154 & up \\
\hline Post-embryonic development & 33.4492 & 45 & 0.0307565 & up \\
\hline Regulation of neuron projection development & 56.4456 & 71 & 0.0355767 & up \\
\hline Embryonic development & 321.949 & 354 & 0.0476929 & up \\
\hline
\end{tabular}

exon 3 and the other containing seven $5 \mathrm{hmC}$ sites within a 557 bp region of the 3' untranslated region (UTR) (Fig. 6a). According to the RNA-Seq data, AMH was expressed in the frontal cortex. We observed increased $5 \mathrm{hmC}$ density in the gene body and a spike in $5 \mathrm{hmC}$ density at the transcription end site (TES), both of which were in agreement with the two clusters found in the $\mathrm{AMH}$ gene. $\mathrm{AMH}$ is associated with gender- 


\section{a)}

\section{5hmC density across chromosomes}

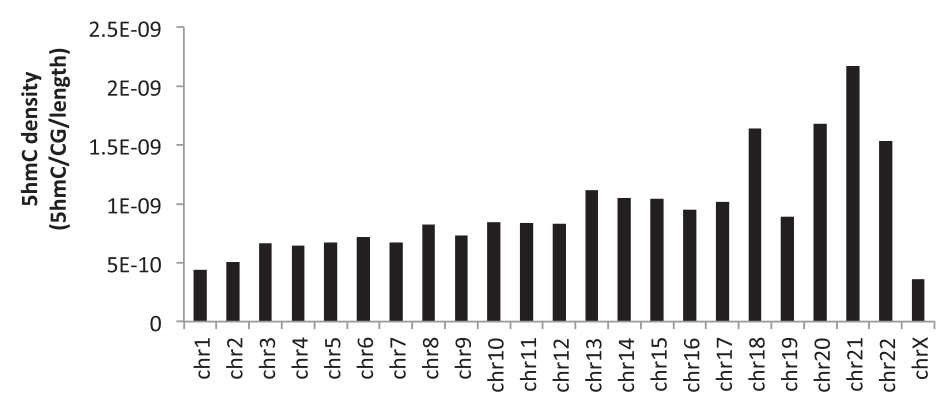

b)

\section{$5 \mathrm{hmC}$ density across chromosomes in males and females}

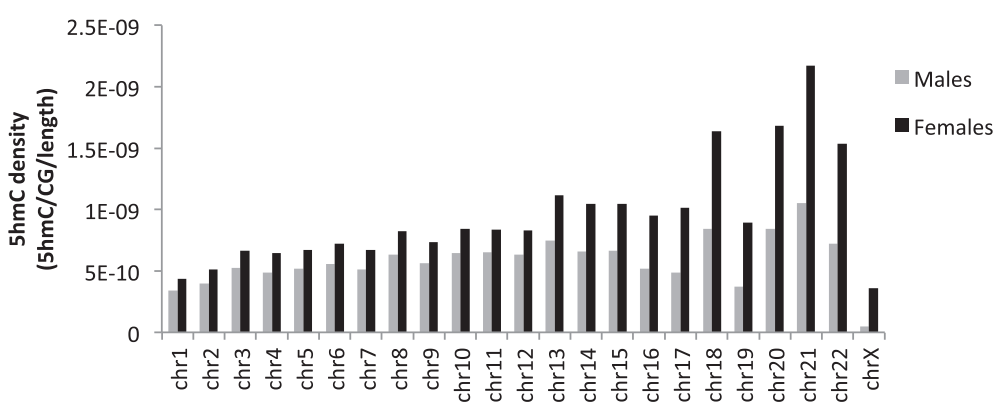

Fig. 5 hmC density in females showed similar patterns as those in males. a Similar to males, 5 hmC density remained stable across chromosomes, with slight increases observed on chromosomes 18, 20, 21, and 22. b 5hmC density between males and females showed similar trends from one chromosome to the next, although gender differences in $5 \mathrm{hmC}$ density became more pronounced as the chromosome size decreased

specific development as it is expressed in males up to puberty to suppress the development of the fallopian tubes and ovaries [29]. In females, however, $\mathrm{AMH}$ is most highly expressed between puberty and menopause, as it recruits primary follicles in the ovaries [29]. Given the hypothesis that $5 \mathrm{hmC}$ is associated with active transcription, one would expect few to no $5 \mathrm{hmC}$ clusters in the $\mathrm{AMH}$ gene in males. Indeed, none of the 65,898 clusters found in the male cluster analysis, using all sites common in at least 10 males, were in the $\mathrm{AMH}$ gene.
Using the publicly available RNA-Seq data [23], we investigated genes showing differential expression between genders (Additional file 8). This data showed the Xlinked zinc finger protein (ZFX) gene on the $\mathrm{X}$ chromosome to be one of the most significantly differentially expressed genes in females $\left(\log _{2} \mathrm{FC}=0.653\right.$; FDRcorrected $P<0.0001)$. Of the 5 hmC clusters unique to females, two are located within the ZFX intergenic region (Fig. 6b). ZFX, which has been shown to escape Xinactivation, is analogous to the Y-linked zinc finger protein (ZFY) on the Y chromosome, and both have been

Table $2 \mathrm{GO}$ terms related to sexual differentiation and development in $5 \mathrm{hmC}$ clusters unique to females

\begin{tabular}{|c|c|c|c|c|}
\hline GO term & Expected & Observed & $p$-value (fdr) & Enrichment \\
\hline Organ morphogenesis & 172.483 & 249 & 2.94E-09 & up \\
\hline Anatomical structure morphogenesis & 362.983 & 462 & 5.47E-08 & up \\
\hline Anatomical structure development & 740.538 & 864 & $5.41 \mathrm{E}-07$ & up \\
\hline System development & 668.472 & 785 & $8.92 \mathrm{E}-07$ & up \\
\hline Organ development & 502.877 & 603 & $2.39 \mathrm{E}-06$ & up \\
\hline Tissue development & 215.405 & 269 & 0.000475655 & up \\
\hline Anatomical structure formation involved in morphogenesis & 121.878 & 161 & 0.0010206 & up \\
\hline Regulation of anatomical structure morphogenesis & 81.6049 & 109 & 0.00786336 & up \\
\hline
\end{tabular}


a)

AMH -- Chr19: 2,249,113 - 2,252,072

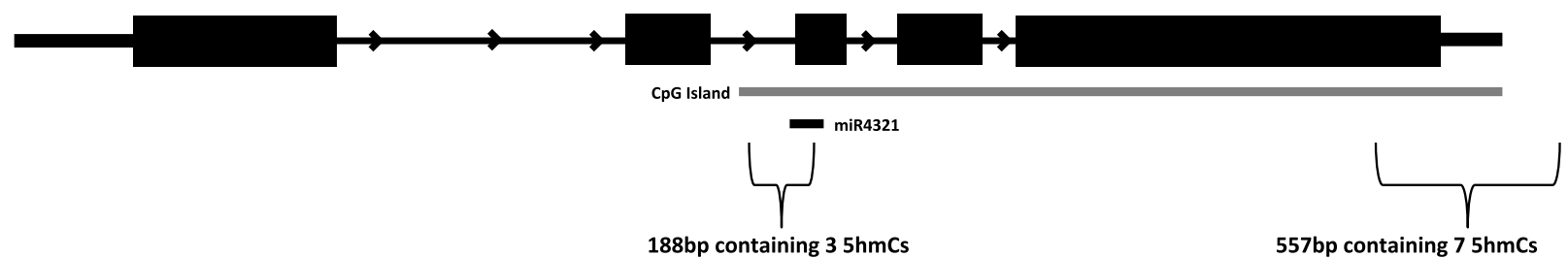

b)

ZFX -- ChrX: 24,167,762 - 24,234,372

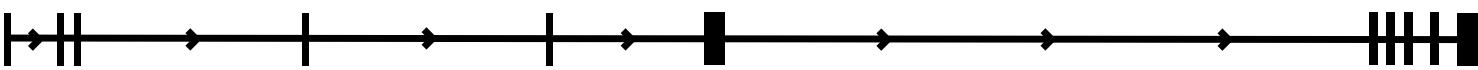

CpG Island

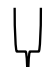

247bp containing $35 \mathrm{hmCs}$

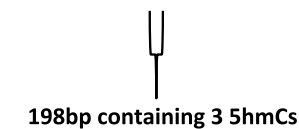

c)

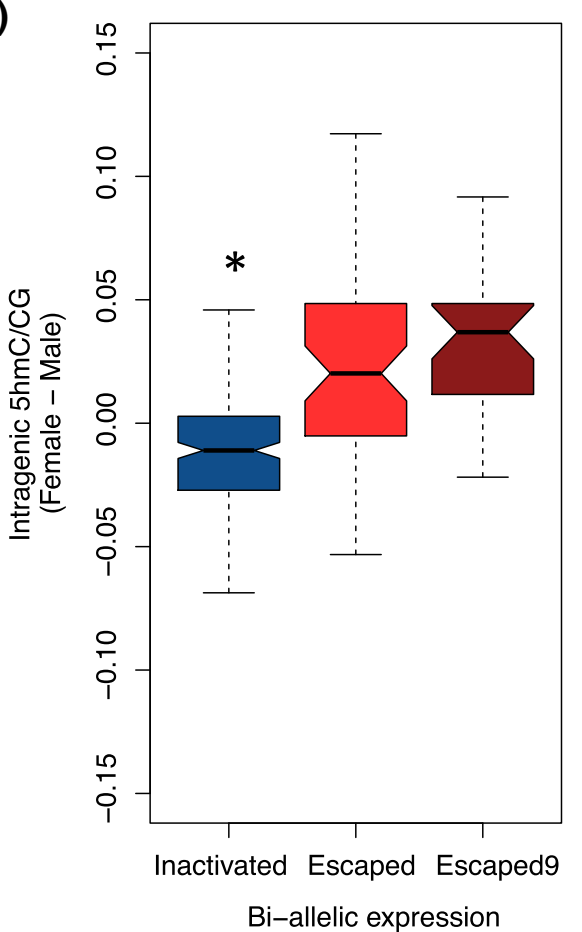

Fig. 6 Cluster analysis of $5 \mathrm{hmC}$ sites unique to females showed clusters related to gender differentiation. a Two $5 \mathrm{hmC}$ clusters unique to females were found in the gene body and 3' UTR of the AMH gene. Both were present within a CpG island, with one also being present around a miRNA binding site. $\mathbf{b} 5 \mathrm{hmC}$ clusters unique to females were also present in the ZFX gene that was differentially expressed in females compared to males $\left(\log _{2} \mathrm{FC}=0.6533 ; \mathrm{FDR} p<0.0001\right)$. c Analysis of $5 \mathrm{hmC}$ density in females also revealed a significant increase in intergenic $5 \mathrm{hmC}$ in genes escaping X-inactivation. Genes most likely to escape (Escaped9) showed a marginal increase in intergenic $5 \mathrm{hmC}$ compared to other levels of potential to escape 
linked to sex determination [30-33]. Similar to AMH, none of the clusters, using all sites common in at least 10 males, were found in the ZFX gene.

\section{Genes escaping X-inactivation show greater gene body $5 \mathrm{hmC}$ density}

Following the results showing gender-specific differentially hydroxymethylated regions (DhmRs) in genes related to sexual anatomical development, we hypothesized that $5 \mathrm{hmC}$ may play a role in additional gender related developmental processes. $5 \mathrm{mC}$ plays an important role in $\mathrm{X}$ inactivation, and previous literature showed that genes escaping X-inactivation have a decrease in promoter CG methylation and an increase in intragenic $\mathrm{CH}$ methylation [8]. Previous studies have separated genes on a scale from 1 to 9 , with 1 and 9 respectively indicating genes least or most likely to escape inactivation. Using all sites found in our female subjects, our results indicated that these same genes that escape $\mathrm{X}$-inactivation also show a significant increase in gene body $5 \mathrm{hmC}$ compared to genes that remain inactivated (Fig. 6c). Furthermore, genes that are most likely to escape $\mathrm{X}$-inactivation showed even greater intergenic $5 \mathrm{hmC}$ density. Although this is only an initial characterization, it provides an interesting avenue for future studies investigating the potential etiology of X-linked diseases or disorders.

\section{Discussion and conclusions}

In this study, we provide a deep characterization of the genomic locations of $5 \mathrm{hmC}$ in the human prefrontal cortex in a large sample. Using AbaSI-Seq, a high-throughput technique, we confirm previously published work using either low-throughput techniques or single samples. Furthermore, we extend the current knowledge of the role of $5 \mathrm{hmC}$ in the brain by linking stable $5 \mathrm{hmC}$ sites to enhancer regions and exon-intron junctions, both of which are involved in gene transcription. We also show the existence of regions of the genome that contain gender-specific $5 \mathrm{hmC}$ patterns, in addition to providing a putative mechanism for how certain genes escape $\mathrm{X}$-inactivation. These data are of interest, as genomic mapping of $5 \mathrm{hmC}$ in the prefrontal cortex will likely be of reference for future studies investigating brain and mental disorders.

Inter-individual variability is common across many fields of study. This is especially true in epigenetics, where both the environment and the genetic landscape are contributing factors in establishing epigenetic features [34-37]. It is, therefore, not surprising to see varying degrees of $5 \mathrm{hmC}$ across the chromosomes and specific genomic features. These findings provide a basis for a dynamic DNA demethylation pathway. More importantly, our data show regions of the genome that are consistently hydroxymethylated in many individuals. These results confirm the stability of $5 \mathrm{hmC}$ in the human genome and provide a foundation for furthering our understanding of the epigenetic properties of $5 \mathrm{hmC}$. Similarly, we show that, in order to increase our understanding of $5 \mathrm{hmC}$, future research will have to be performed on large samples. Furthermore, increased stringency of bioinformatics analyses will reduce levels of random variability, thereby enhancing the power of studies to infer biological relevance from the $5 \mathrm{hmC}$ sequencing data.

In this study, we show that an intermediate level of stringency, defined as $5 \mathrm{hmC}$ sites present in at least half the total sample, was appropriate in discovering regions with a consistently high density of $5 \mathrm{hmC}$ across subjects. Our results provide reliable evidence that $5 \mathrm{hmC}$ is associated with gene regulatory features, such as enhancer regions and histone marks that associate with active gene transcription. Furthermore, we add to the available data in mammalian cells and tissues showing a clear correlation between gene body $5 \mathrm{hmC}$ and highly expressed genes. Finally, our cluster analyses show an increased density of $5 \mathrm{hmC}$ in genes associated with many developmental processes, specifically those related to neurogenesis and nervous system development. These results are of interest considering the many publications that have linked $5 \mathrm{hmC}$ to neurodevelopment, neurodegenerative, and neuropsychiatric phenotypes, and are consistent with the role of $5 \mathrm{hmC}$ and $5 \mathrm{mC}$ in tissue-specific gene regulation [7, 38], thus supporting the internal validity of our findings. Although the exact function of $5 \mathrm{hmC}$ remains unknown, our findings lend to the idea that $5 \mathrm{hmC}$ may act as an epigenetic mark by regulating gene transcription.

In addition to characterizing $5 \mathrm{hmC}$ in a large sample, we also provide evidence to suggest that $5 \mathrm{hmC}$ may be an important factor in anatomical development. Not only do GO analyses of unique DhmRs in females show clusters of $5 \mathrm{hmC}$ on genes associated with genderspecific properties and functions, but our results also indicate that genes escaping $\mathrm{X}$-inactivation have increased intragenic $5 \mathrm{hmC}$ density. Early research into $5 \mathrm{hmC}$ and TET proteins showed specific properties of each based on developmental stages. For example, TET1 and TET 2 are more highly expressed in primordial germ cells, while TET3 is primary found in zygotes $[39,40]$. Similarly, levels of $5 \mathrm{hmC}$ tend to be high in zygotes, decrease rapidly during cell division, and are reestablished in the blastocyst [41]. Interestingly, TET protein knockdown and knockout experiments show that TET proteins appear to have redundant and compensatory roles in establishing $5 \mathrm{hmC}$ patterns $[40,42,43]$. As such, although the exact function of $5 \mathrm{hmC}$ in development remains unclear, the presence of gender-specific DhmRs highlights the putative roles of $5 \mathrm{hmC}$ and TET proteins in embryonic and adult development. 
Whether $5 \mathrm{hmC}$ is solely an intermediate molecule in the process of DNA demethylation or whether this 6th DNA base may have additional regulatory properties is a question that remains at the forefront of $5 \mathrm{hmC}$ research. Recent literature has shown that the oxidation of $5 \mathrm{mC}$ to $5 \mathrm{hmC}$ occurs on the parental strand after replication, and in the presence of a stable pool of $5 \mathrm{hmC}$ in multiple tissues from adult mice [44]. Furthermore, several studies have shown the existence of $5 \mathrm{hmC}$ in RNA, from archaeal species to mammalian cells, that occurs through the TET-mediated oxidation of $5 \mathrm{mC}[45,46]$. Certainly, although $5 \mathrm{hmC}$ marks may continue through the oxidation pathway and ultimately lead to a demethylated cytosine, mounting evidence, including those presented here, all suggest that $5 \mathrm{hmC}$ does regulate gene transcription. Its mechanism of action, however, remains to be elucidated.

In addition to providing characterizations of $5 \mathrm{hmC}$ genomic location and function, we also confirm the efficacy of a high-throughput method to appropriately detect $5 \mathrm{hmC}$ sites at single base resolution. AbaSI-Seq, which has been used previously in embryonic stem cells, bases itself on a $5 \mathrm{hmC}$-sensitive restriction enzyme digestion. This technique is valuable as it avoids the biases caused by antibody-based approaches [47] and does not cause DNA damage like other methods that employ bisulfite conversion [48]. Furthermore, AbaSI has independently been shown to recognize both glucosylated and non-glucosylated $5 \mathrm{hmC}$ [49], thereby increasing its validity as an effective tool in studying $5 \mathrm{hmC}$.

In summary, this manuscript provides a comprehensive assessment of $5 \mathrm{hmC}$ in human prefrontal cortex using a high-throughput technique. Moreover, we provide a reference for comparison of $5 \mathrm{hmC}$ in other mammalian species, and shed light on potential avenues of interest for further research in determining the functional relevance of $5 \mathrm{hmC}$.

\section{Methods}

\section{Subjects}

Post-mortem human brain tissue from the prefrontal cortex was obtained from the Douglas - Bell Canada Brain Bank. The prefrontal cortex was chosen given its diverse functions relative to human cognition and of importance to neuropsychiatric phenotypes. Additionally, the prefrontal cortex has been widely implicated in a variety of mental illnesses through dysregulation of epigenetic mechanisms [50-56]. Brain tissue used in this study was dissected at $4{ }^{\circ} \mathrm{C}$, snap-frozen in liquid nitrogen, and stored at $-80^{\circ} \mathrm{C}$ following standard procedures. The Quebec Coroner's office assessed the cause of death for each subject, and subsequently, we obtained information on the subjects' mental health using psychological autopsies using the Structured Clinical Interviews for
DSM-IV Axis 1 [57]. In addition, brain tissue samples from all subjects were assessed for absence of pathological processes by a neuropathologist. Subjects died from either natural $(n=11)$ or accidental $(n=13)$ causes, and all were psychiatrically and neurologically healthy. All subjects were French-Canadian. Mean age was $43.33 \pm 4.46$ years. Written informed consent was obtained from next-of-kin for all subjects, and the Douglas Institute Research Ethics Board approved this study.

\section{AbaSI-Seq}

Genomic DNA was extracted from the prefrontal cortex using QIAGEN's QIAamp DNA Mini Kit (QIAGEN, cat. \# 51304). Concentrations of genomic DNA were assessed using the Thermo Scientific Nanodrop 1000 spectrophotometer and each sample had a 260/280 ratio greater than 1.8. AbaSI-Seq library construction was performed as described previously [19]. Briefly, DNA was glucosylated by using UDP-glucose and T4- $\beta$-glucosyltransferase (New England Biolabs, cat. \#M0357L). The DNA was then digested using AbaSI (New England Biolabs, cat. \#R0665S) and custom biotinylated adaptors were ligated to DNA ends. The DNA was then sheared using the Covaris S220 Focused-Ultrasonicator (peak incident power $=140$; duty $\%=10$; cycles per burst = 200; time $=120 \mathrm{~s}$ ). Sheared DNA was captured using Dynabeads ${ }^{\odot}$ MyOne $^{\mathrm{Tm}}$ Streptavidin C1 beads (Life Technologies, cat. \# 65001). NEBNext ${ }^{\mathrm{Tm}}$ End Repair Module (New England Biolabs, cat. \#E6050L) and NEBNext ${ }^{\mathrm{TM}} \mathrm{dA}$-Tailing Module (New England Biolabs, cat. \#E6053L) were used to generate blunt ended fragments and create an adenosine tail, respectively. A second set of custom adaptors were ligated to the DNA, followed by PCR amplification using NEBNext ${ }^{\mathrm{TM}}$ High-Fidelity 2x PCR Master Mix (New England Biolabs, cat. \#E6013AA). Illumina TruSeq indices 1 through 12 were used to barcode samples. 50 cycle, single-read sequencing was performed on Illumina's HiSeq 2000. A minimum of 60,000,000 sequencing reads was obtained per subject. Sequencing quality control metrics can be found in Additional file 1.

\section{Data processing}

FASTQ reads were filtered based on a quality score greater than 30 and were then aligned to the human reference genome (UCSC Hg19) using Bowtie 2 (http://bowtiebio.sourceforge.net/bowtie2/index.shtml), with the preset parameters of very-sensitive (-D 20 - $\mathrm{R} \quad 3$ - N 0 - $-\mathrm{L} 20$-i $\mathrm{S}, 1,0.50)$. Duplicates were removed using Picard (http:// broadinstitute.github.io/picard/) and realignment was performed using the GATK alignment procedures from the Broad Institute (https://www.broadinstitute.org/gatk/). Subsequent filtering of aligned reads was based on a quality score of greater or equal to $10.5 \mathrm{hmC}$ sites were identified using a custom PERL script [19] that detected potential $5 \mathrm{hmC}$ sites based on their expected distance 
from the AbaSI enzymatic cleavage site. A combination of BEDtools, R packages, and custom scripts were used for downstream analyses. Exact specifications are found below.

\section{Density plots \\ Chromosomes}

All $5 \mathrm{hmC}$ sites in the intermediate stringency were used to assess chromosomal $5 \mathrm{hmC}$ density. Density was defined as the total number of $5 \mathrm{hmC}$ sites per chromosome, corrected for the length of the chromosome and the total number of CGs on the chromosome.

\section{Genetic features}

$5 \mathrm{hmC}$ sites in the intermediate stringency category were plotted against genomic regions and corrected for the length of the region and the number of CGs within the region. All genomic features were defined based on the GRCh37/hg19 genomic annotation downloaded from the UCSC database. Different genic elements, including transcription start sites (TSS), exons, introns, and transcription end sites (TES), were defined based on the Ensembl (release 75). Since genes can have multiple transcripts, we selected the 5'-most TSS on the positive strand as the single TSS associated with each gene. The reverse (3' most TSS) was done for genes on the negative strand. We limited downstream analysis to proteincoding genes, resulting in 20,745 TSSs in total. Similarly, annotations for retro-elements (i.e., LINEs and SINEs) and $\mathrm{CpG}$ islands were acquired from the UCSC database. CpG shores were defined as the $2 \mathrm{~kb}$ flanking a CpG island. Coordinates of predicted of promoter and enhancer regions were obtained from recently published genome-wide maps of chromatin states in the adult brain midfrontal lobe [22], including H3K4me3, H3K4me1 and H3K27ac. Two types of enhancers were distinguished: active enhancers that were simultaneously marked by distal H3K4me1 and H3K27ac, and poised enhancers that were solely marked by distal H3K4me1 $[9,58]$.

\section{ChIP-Seq peaks}

To plot $5 \mathrm{hmC}$ profiles around ChIP-Seq peaks, the mean $5 \mathrm{hmC}$ was calculated for each contiguous $100 \mathrm{bp}$ bin from $3 \mathrm{~kb}$ upstream to $3 \mathrm{~kb}$ downstream of the central position of the peak.

\section{RNA-Seq}

Gene expression counts were obtained from RNA-seq data from the preferontal cortex of 11 controls subjects from previously published work [23]. Genes were then classified into quartiles based on their basal gene expression levels: 1st quartile is lowest and 4th is highest. Gene bodies and $20 \mathrm{~kb}$ regions upstream and downstream were each divided into 50 intervals. We gathered hydroxymethylation data from windows within each of these intervals and plotted the mean hydroxymethylation level for all windows overlapping each position.

\section{Exon-intron boundaries}

A total of 144,157 internal exons representing 20,745 genes were retrieved from the Ensembl database, with exclusion of all first and last exons and single-exon genes. $5 \mathrm{hmC}$ count was plotted against the 20 bp flanking the $5^{\prime}$ and 3' exon-intron boundaries on both the sense and antisense strands.

\section{Cluster analyses and gene ontology (GO)}

Cluster analyses were performed using online software. Briefly, a region was deemed to have a cluster of $5 \mathrm{hmC}$ if there were at least three $5 \mathrm{hmCs}$ each within $200 \mathrm{bp}$ of each other. $5 \mathrm{hmC}$ clusters was located within a gene body were assigned to that gene, otherwise $5 \mathrm{hmC}$ cluster were assigned to the closest TSS from the center position of the $5 \mathrm{hmC}$ cluster. GeneTrail [28] was used to test for enrichment of functional annotations among genes nearby $5 \mathrm{hmC}$ clusters $(<250 \mathrm{~kb})$, using the set of all Ensembl genes as a background. Analysis was done with default parameters and results corrected for multiple testing by the method of Benjamini and Hochberg to control the False Discovery Rate (FDR). GO terms were deemed significant if they had an FDRcorrected $P \leq 0.05$. The background set included all protein-coding genes.

\section{Gender analyses}

\section{Cluster analyses for sites unique to females}

$5 \mathrm{hmC}$ sites in all 5 females were compared to $5 \mathrm{hmC}$ sites detected in all 19 males. Cluster analyses, as described above, were performed using only the $5 \mathrm{hmC}$ sites unique to females.

\section{Cluster analyses for sites unique to males}

5 randomly selected sets of 5 males were used to determine male-specific $5 \mathrm{hmC}$ clusters. Briefly, all $5 \mathrm{hmC}$ sites in each set, separately, were compared to $5 \mathrm{hmC}$ sites in all 5 females. Cluster analyses, as described above, were performed in each set using only the $5 \mathrm{hmC}$ sites unique to the males in the respective set. Only the clusters that were common in all of the 5 sets of males were deemed to be male-specific.

\section{X-inactivation}

Genes involved in X-chromosome inactivation were taken from previously published data [59]. Briefly, surveyed genes were given a score from 0-9 based on the number of individual hybrid lines detected from the inactivated $\mathrm{X}$ chromosome. A score of 0 corresponds to complete 
inactivation, whereas a score of 9 corresponds to complete escape from $\mathrm{X}$-inactivation. Intragenic $5 \mathrm{hmC}$ patterns on human X-linked genes were then compared between our female and male subjects.

\section{Availability of supporting data}

The data sets supporting the results of this article will be deposited in the GEO database.

\section{Additional files}

Additional file 1: is a table containing sequencing quality control metrics. (PDF $38 \mathrm{~kb}$ )

Additional file 2: is a histogram showing the number of $5 \mathrm{hmC}$ sites common across subjects using AbaSl-Seq. Genomic locations of $5 \mathrm{hmC}$ showed high inter-individual variability across all subjects. Stringency categories for downstream analyses were selected based on sample size. Low stringency $=$ sites present in at least $25 \%$ of subjects; intermediate stringency $=$ sites present in at least $50 \%$ of subjects; high stringency = sites present in at least $75 \%$ of subjects. (PDF $40 \mathrm{~kb}$ )

Additional file 3: is a histogram showing the number of $5 \mathrm{mC}$ sites common across a different set of subjects using WGBS. Genomic locations of $5 \mathrm{mC}$ showed high degree of inter-individual stability across subjects. Analysis of whole-genome bisulfite sequencing data showed considerable stability in the number of $5 \mathrm{mC}$ sites common in 5,10 , and 15 individuals. (PDF $38 \mathrm{~kb}$ )

Additional file 4: shows the percent of CGs on autosomal chromosomes that contain a $5 \mathrm{hmC}$ mark. $5 \mathrm{hmC}$ content on autosomal chromosomes showed significant decreases from one stringency to the next. One-way ANOVA $\left(F_{(2,65)}=372.0 ; p<0.0001\right)$ with Tukey's Multiple Comparison Test $(p<0.05)$ showed significant decreases in the percent of CGs that can be hydroxymethylated on autosomal chromosomes. Low = Low stringency; Inter = Intermediate stringency; High = High Stringency. (PDF 72 kb)

Additional file 5: is a table containing GO terms from a cluster analysis using all $5 \mathrm{hmC}$ sites in the intermediate stringency. (PDF $110 \mathrm{~kb}$ )

Additional file 6: is a table containing the GO terms from a cluster analysis using $5 \mathrm{hmC}$ sites unique to males. (PDF $90 \mathrm{~kb}$ )

Additional file 7: is a table containing the GO terms from a cluster analysis using $5 \mathrm{hmC}$ sites unique to females. (PDF $71 \mathrm{~kb}$ )

Additional file 8: is a table containing the results of a differential analysis of gene expression in males and females using previously published RNA-Seq data [23]. (PDF $76 \mathrm{~kb}$ )

\section{Abbreviations}

5hmC: 5-hydroxymethylcytosine; 5mC: 5-methylcytosine; TET: Ten-eleven translocation; TAB-Seq: Tet-assisted bisulfite sequencing; WGBS: Whole genome bisulfite sequencing; TSS: Transcription start sites; LINES: Long interspersed elements; SINEs: Short interspersed elements; CTCF: CCCTC-binding factor; GO: Gene ontology; AMH: Anti-Müllerian Hormone; UTR: Untranslated region; TES: Transcription end site; ZFX: X-linked zinc finger protein; ZFY: Y-linked zinc finger protein; DhmRs: Differentially hydroxymethylated regions.

\section{Competing interests}

The authors declare no competing interests.

\section{Authors' contributions}

JAG, GGC, CE, and GT designed the study. JAG and GGC performed all laboratory experiments. JAG, AP, LBB, and CE performed all bioinformatics and data analyses. J.A.G. and G.T. wrote the manuscript. All authors discussed the results and contributed to the manuscript. All authors read and approved the final manuscript.

\section{Acknowledgements}

This study benefited from access to tissue from the Douglas-Bell Canada Brain Bank, which is supported by the Réseau québécois sur le suicide, les troubles de l'humeur et les troubles associés and Brain Canada. J.A.G. is supported by a CIHR Frederick Banting And Charles Best Doctoral fellowship. GT is supported by grants from the Canadian Institute of Health Research MOP93775,

MOP11260, MOP119429, and MOP119430; from the National Institutes of Health 1R01DA033684-01; and by the Fonds de Recherche du Québec - Santé through a Chercheur National salary award and through the Quebec Network on Suicide, Mood Disorders, and Related Disorders.

\section{Author details}

'McGill Group for Suicide Studies, Douglas Mental Health University Institute, 6875 boul. Lasalle, Montreal, Quebec, Canada. ${ }^{2}$ Department of Genetics, CHU Sainte-Justine Research Centre, 3175 Chemin de la Côte-Sainte-Catherine, Montreal, Quebec, Canada. ${ }^{3}$ Departments of Biochemistry and Pediatrics, University of Montreal, 2900 Boulevard Edouard-Montpetit, Montreal, Quebec, Canada.

Received: 15 July 2015 Accepted: 24 August 2015

Published online: 03 September 2015

\section{References}

1. Tahiliani M, Koh KP, Shen Y, Pastor WA, Bandukwala H, Brudno Y, et al. Conversion of 5-methylcytosine to 5-hydroxymethylcytosine in mammalian DNA by MLL partner TET1. Science. 2009;324(5929):930-5.

2. Kriaucionis $\mathrm{S}$, Heintz $\mathrm{N}$. The nuclear DNA base 5-hydroxymethylcytosine is present in Purkinje neurons and the brain. Science. 2009;324(5929):929-30.

3. Ito S, D'Alessio AC, Taranova OV, Hong K, Sowers LC, Zhang Y. Role of Tet proteins in $5 \mathrm{mC}$ to $5 \mathrm{hmC}$ conversion, ES-cell self-renewal and inner cell mass specification. Nature. 2010;466(7310):1129-33.

4. Li W, Liu M. Distribution of 5-hydroxymethylcytosine in different human tissues. J Nucleic Acids. 2011;2011:870726.

5. Kinney SM, Chin HG, Vaisvila R, Bitinaite J, Zheng Y, Esteve PO, et al. Tissuespecific distribution and dynamic changes of 5-hydroxymethylcytosine in mammalian genomes. J Biol Chem. 2011;286(28):24685-93.

6. Nestor CE, Ottaviano R, Reddington J, Sproul D, Reinhardt D, Dunican D, et al. Tissue type is a major modifier of the 5-hydroxymethylcytosine content of human genes. Genome Res. 2012;22(3):467-77.

7. Mellen M, Ayata P, Dewell S, Kriaucionis S, Heintz N. MeCP2 binds to $5 \mathrm{hmC}$ enriched within active genes and accessible chromatin in the nervous system. Cell. 2012;151(7):1417-30.

8. Lister R, Mukamel EA, Nery JR, Urich M, Puddifoot CA, Johnson ND, et al. Global epigenomic reconfiguration during mammalian brain development. Science. 2013;341(6146):1237905.

9. Wen L, Li X, Yan L, Tan Y, Li R, Zhao Y, et al. Whole-genome analysis of 5-hydroxymethylcytosine and 5-methylcytosine at base resolution in the human brain. Genome Biol. 2014;15(3):R49.

10. Gabel HW, Kinde B, Stroud H, Gilbert CS, Harmin DA, Kastan NR, et al. Disruption of DNA-methylation-dependent long gene repression in Rett syndrome. Nature. 2015;522:89-3.

11. Szulwach KE, Li X, Li Y, Song CX, Wu H, Dai Q, et al. 5-hmC-mediated epigenetic dynamics during postnatal neurodevelopment and aging. Nat Neurosci. 2011;14(12):1607-16.

12. Hahn MA, Qiu R, Wu X, Li AX, Zhang H, Wang J, et al. Dynamics of 5-hydroxymethylcytosine and chromatin marks in Mammalian neurogenesis. Cell reports. 2013;3(2):291-300.

13. Coppieters N, Dieriks BV, Lill C, Faull RL, Curtis MA, Dragunow M. Global changes in DNA methylation and hydroxymethylation in Alzheimer's disease human brain. Neurobiol Aging. 2014;35(6):1334-44.

14. Zhubi A, Chen Y, Dong E, Cook EH, Guidotti A, Grayson DR. Increased binding of MeCP2 to the GAD1 and RELN promoters may be mediated by an enrichment of 5-hmC in autism spectrum disorder (ASD) cerebellum. Transcult Psychiatry. 2014;4:e349.

15. Villar-Menendez I, Blanch M, Tyebji S, Pereira-Veiga T, Albasanz JL, Martin M, et al. Increased 5-methylcytosine and decreased 5-hydroxymethylcytosine levels are associated with reduced striatal A2AR levels in Huntington's disease. Neruomol Med. 2013;15(2):295-309.

16. Dong E, Gavin DP, Chen Y, Davis J. Upregulation of TET1 and downregulation of $A P O B E C 3 A$ and $A P O B E C 3 C$ in the parietal cortex of psychotic patients. Transcult Psychiatry. 2012;2:e159. 
17. Wang F, Yang Y, Lin X, Wang JQ, Wu YS, Xie W, et al. Genome-wide loss of $5-\mathrm{hmC}$ is a novel epigenetic feature of Huntington's disease. Hum Mol Genet. 2013;22(18):3641-53.

18. Yao B, Lin L, Street RC, Zalewski ZA, Galloway JN, Wu H, et al. Genome-wide alteration of 5-hydroxymethylcytosine in a mouse model of fragile X-associated tremor/ataxia syndrome. Hum Mol Genet. 2014;23(4):1095-107.

19. Sun Z, Terragni J, Borgaro JG, Liu Y, Yu L, Guan S, et al. High-resolution enzymatic mapping of genomic 5-hydroxymethylcytosine in mouse embryonic stem cells. Cell reports. 2013;3(2):567-76.

20. Szulwach KE, Li X, Li Y, Song CX, Han JW, Kim S, et al. Integrating 5-hydroxymethylcytosine into the epigenomic landscape of human embryonic stem cells. PLoS Genet. 2011;7(6):e1002154.

21. Stroud H, Feng S, Morey Kinney S, Pradhan S, Jacobsen SE. 5-Hydroxymethylcytosine is associated with enhancers and gene bodies in human embryonic stem cells. Genome Biol. 2011;12(6):R54.

22. Zhu J, Adli M, Zou JY, Verstappen G, Coyne M, Zhang X, et al. Genome-wide chromatin state transitions associated with developmental and environmental cues. Cell. 2013;152(3):642-54.

23. Akula N, Barb J, Jiang X, Wendland JR, Choi KH, Sen SK, et al. RNAsequencing of the brain transcriptome implicates dysregulation of neuroplasticity, circadian rhythms and GTPase binding in bipolar disorder. Mol Psychiatry. 2014;19(11):1179-85.

24. Khare T, Pai S, Koncevicius K, Pal M, Kriukiene E, Liutkeviciute Z, et al. 5-hmC in the brain is abundant in synaptic genes and shows differences at the exon-intron boundary. Nat Struct Mol Biol. 2012;19(10):1037-43.

25. Shukla S, Kavak E, Gregory M, Imashimizu M, Shutinoski B, Kashlev M, et al. CTCF-promoted RNA polymerase II pausing links DNA methylation to splicing. Nature. 2011;479(7371):74-9.

26. Feldmann A, Ivanek R, Murr R, Gaidatzis D, Burger L, Schubeler D. Transcription factor occupancy can mediate active turnover of DNA methylation at regulatory regions. PLoS Genet. 2013;9(12):e1003994.

27. Gao F, Xia Y, Wang J, Luo H, Gao Z, Han X, et al. Integrated detection of both 5-mC and 5-hmC by high-throughput tag sequencing technology highlights methylation reprogramming of bivalent genes during cellular differentiation. Epigenetics. 2013;8(4):421-30.

28. Backes C, Keller A, Kuentzer J, Kneissl B, Comtesse N, Elnakady YA, et al. GeneTrail-advanced gene set enrichment analysis. Nucleic Acids Res. 2007:35(Web Server issue):W186-92

29. Zec I, Tislaric-Medenjak D, Megla ZB, Kucak I. Anti-Mullerian hormone: a unique biochemical marker of gonadal development and fertility in humans. Biochemia medica. 2011;21(3):219-30.

30. Schneider-Gadicke A, Beer-Romero P, Brown LG, Nussbaum R, Page DC. ZFX has a gene structure similar to ZFY, the putative human sex determinant, and escapes X inactivation. Cell. 1989;57(7):1247-58.

31. Palmer MS, Berta P, Sinclair AH, Pym B, Goodfellow PN. Comparison of human ZFY and ZFX transcripts. Proc Natl Acad Sci U S A. 1990;87(5):1681-5.

32. Erickson RP, Zwingman T, Ao A. Gene expression, X-inactivation, and methylation during spermatogenesis: the case of Zfa, Zfx, and Zfy in mice. Mol Reprod Dev. 1993;35(2):114-20.

33. Mayer A, Lahr G, Swaab DF, Pilgrim C, Reisert I. The Y-chromosomal genes SRY and ZFY are transcribed in adult human brain. Neurogenetics. 1998;1(4):281-8.

34. Lienert F, Wirbelauer C, Som I, Dean A, Mohn F, Schubeler D. Identification of genetic elements that autonomously determine DNA methylation states. Nat Genet. 2011;43(11):1091-7.

35. McVicker G, van de Geijn B, Degner JF, Cain CE, Banovich NE, Raj A, et al. Identification of genetic variants that affect histone modifications in human cells. Science. 2013;342(6159):747-9.

36. Kasowski M, Kyriazopoulou-Panagiotopoulou S, Grubert F, Zaugg JB, Kundaje A, Liu Y, et al. Extensive variation in chromatin states across humans. Science. 2013;342(6159):750-2.

37. Kilpinen H, Waszak SM, Gschwind AR, Raghav SK, Witwicki RM, Orioli A, et al. Coordinated effects of sequence variation on DNA binding, chromatin structure, and transcription. Science. 2013;342(6159):744-7.

38. Pai AA, Bell JT, Marioni JC, Pritchard JK, Gilad Y. A genome-wide study of DNA methylation patterns and gene expression levels in multiple human and chimpanzee tissues. PLoS Genet. 2011;7(2):e1001316.

39. Hajkova P, Jeffries SJ, Lee C, Miller N, Jackson SP, Surani MA. Genome-wide reprogramming in the mouse germ line entails the base excision repair pathway. Science. 2010;329(5987):78-82.
40. Gu TP, Guo F, Yang H, Wu HP, Xu GF, Liu W, et al. The role of Tet3 DNA dioxygenase in epigenetic reprogramming by oocytes. Nature. 2011;477(7366):606-10.

41. Ruzov A, Tsenkina Y, Serio A, Dudnakova T, Fletcher J, Bai Y, et al. Lineagespecific distribution of high levels of genomic 5-hydroxymethylcytosine in mammalian development. Cell Res. 2011;21(9):1332-42.

42. Dawlaty MM, Breiling A, Le T, Raddatz G, Barrasa MI, Cheng AW, et al. Combined deficiency of Tet1 and Tet2 causes epigenetic abnormalities but is compatible with postnatal development. Dev Cell. 2013;24(3):310-23.

43. Dawlaty MM, Ganz K, Powell BE, Hu YC, Markoulaki S, Cheng AW, et al. Tet is dispensable for maintaining pluripotency and its loss is compatible with embryonic and postnatal development. Cell Stem Cell. 2011;9(2):166-75.

44. Bachman M, Uribe-Lewis S, Yang X, Williams M, Murrell A, Balasubramanian S. 5-Hydroxymethylcytosine is a predominantly stable DNA modification. Nat Chem. 2014;6(12):1049-55.

45. Fu L, Guerrero CR, Zhong N, Amato NJ, Liu Y, Liu S, et al. Tet-mediated formation of 5-hydroxymethylcytosine in RNA. J Am Chem Soc. 2014;136(33):11582-5.

46. Huber SM, van Delft $P$, Mendil L, Bachman M, Smollett $K$, Werner F, et al. Formation and Abundance of 5-Hydroxymethylcytosine in RNA. Chembiochem. 2015;16:752-5.

47. Thomson JP, Hunter JM, Nestor CE, Dunican DS, Terranova R, Moggs JG, et al. Comparative analysis of affinity-based 5-hydroxymethylation enrichment techniques. Nucleic Acids Res. 2013;41(22):e206.

48. Grunau C, Clark SJ, Rosenthal A. Bisulfite genomic sequencing: systematic investigation of critical experimental parameters. Nucleic Acids Res. 2001;29(13):E65-65.

49. Horton JR, Borgaro JG, Griggs RM, Quimby A, Guan S, Zhang X, et al. Structure of 5-hydroxymethylcytosine-specific restriction enzyme, AbaSI, in complex with DNA. Nucleic Acids Res. 2014;42(12):7947-59.

50. Cheung I, Shulha HP, Jiang Y, Matevossian A, Wang J, Weng Z, et al. Developmental regulation and individual differences of neuronal H3K4me3 epigenomes in the prefrontal cortex. Proc Natl Acad Sci U S A. 2010;107(19):8824-9.

51. Shulha HP, Cheung I, Whittle C, Wang J, Virgil D, Lin CL, et al. Epigenetic signatures of autism: trimethylated H3K4 landscapes in prefrontal neurons. Arch Gen Psychiatry. 2012;69(3):314-24.

52. Numata $S$, Ye T, Hyde TM, Guitart-Navarro X, Tao R, Wininger M, et al. DNA methylation signatures in development and aging of the human prefrontal cortex. Am J Hum Genet. 2012;90(2):260-72.

53. Gross JA, Fiori LM, Labonte B, Lopez JP, Turecki G. Effects of promoter methylation on increased expression of polyamine biosynthetic genes in suicide. J Psychiatr Res. 2012;47:513-9.

54. Cruceanu C, Alda M, Nagy C, Freemantle E, Rouleau GA, Turecki G. H3K4 trimethylation in synapsin genes leads to different expression patterns in bipolar disorder and major depression. Int J Neuropsychopharmacol. 2013;16(2):289-99.

55. Nagy C, Suderman M, Yang J, Szyf M, Mechawar N, Ernst C, et al. Astrocytic abnormalities and global DNA methylation patterns in depression and suicide. Mol Psychiatry. 2014;20:320-8.

56. Lopez JP, Lim R, Cruceanu C, Crapper L, Fasano C, Labonte B, et al. miR-1202 is a primate-specific and brain-enriched microRNA involved in major depression and antidepressant treatment. Nat Med. 2014;20(7):764-8.

57. Dumais A, Lesage AD, Lalovic A, Seguin M, Tousignant M, Chawky N, et al. Is violent method of suicide a behavioral marker of lifetime aggression? Am J Psychiatry. 2005;162(7):1375-8.

58. Creyghton MP, Cheng AW, Welstead GG, Kooistra T, Carey BW, Steine EJ, et al. Histone H3K27ac separates active from poised enhancers and predicts developmental state. Proc Natl Acad Sci U S A. 2010;107(50):21931-6.

59. Carrel L, Willard HF. X-inactivation profile reveals extensive variability in X-linked gene expression in females. Nature. 2005;434(7031):400-4. 